\title{
LEGITIMAÇÃO A PARTIR DOCONTRATO OU COM OCONTRATO: ACERCA DOS MODELOS DE FUNDAMENTAÇÃO POLÍTICA DE RAWLS E DE DWORKIN
}

\author{
Carlos A. Ferraz \\ Universidade Federal de Pelotas
}

\begin{abstract}
This article intends to explore the Liberal thought as it is expressed in Rawls's and Dworkin's Political Philosophy. We begin with Dworkin's critique to the rawlsian concept of "original position" (and with his critique to the contractualism as a whole as well) in order to show how Dworkin establish his own thought in a kind of mitigated contractualism.
\end{abstract}

Keywords: Contractualism; contemporary political philosophy; liberalism.

Resumo: Este artigo pretende explorar o pensamento liberal tal como este está expresso na filosofia política de Rawls e Dworkin. Começamos com a crítica de Dworkin ao conceito rawlseano de "posição original" (e também com sua crítica ao contratualismo como um todo) para mostrar como Dworkin estabelece seu próprio pensamento como um tipo de contratualismo mitigado.

Palavras-chave: Contratualismo; filosofia política contemporânea; liberalismo.

Não há dúvidas de que o modelo contratualista é um dos mais consistentes no tocante à fundamentação da política. Seja na antigüidade (em uma espécie de proto-contratualismo, em Platão $^{1}$ ), seja na modernidade ${ }^{2}$ (período

\footnotetext{
1 Tal "proto-contratualismo" é identificado, por exemplo, na "República", de Platão, especialmente no contexto em que lemos: "Uma cidade nasce, parece-me, porque cada um de nós não é auto-suficiente, mas carente de muitas coisas (...). Assim, se um homem chama outro para ajudá-lo em uma necessidade e um outro em uma outra, já que precisam de muitas coisas, reúnem muitos em um único lugar de morada, tendo-os como companheiros e auxiliares, a essa vida comum damos o nome de cidade" (PLATÃO. A República. São Paulo: Martins Fontes, 2006, 369a, p. 62). Dessa forma, em tal obra já encontraríamos uma defesa da necessidade de regras para uma harmonia social, harmonia na qual realizaríamos, por assim dizer, nosso telos (em Rawls falamos, mais apropriadamente, numa 'concepção de bem' - good).
} 
no qual tal modelo atinge seu ápice em autores tais quais Hobbes, Rousseau, Locke e Kant), tal modelo mostra-se, nas suas mais variadas formas, como uma tentadora maneira de sustentar-se a validade (legitimidade) de um determinado estado de direito (sociedade civil).

Todavia, há, obviamente, uma espécie de polissemia do conceito de contrato. Ele tem acepções específicas conforme o modelo de sociedade civil que se intenta fundamentar. No contexto contemporâneo, que é o que nos interessa aqui, não há dúvida de que o modelo proposto por John Rawls é um dos mais sólidos e fomentador de debates, tendo gerado toda uma tradição em discussão acerca de temas caros à filosofia política. Imbuído pela tradição contratualista (e liberal) que remonta a Locke, Rousseau e Kant ${ }^{3}$, Rawls concilia tal modelo com seus próprios pressupostos liberais (com sua, digamos, 'cultura política pública'). Aliás, também nessa tradição kantiana temos, por exemplo, T.M. Scanlon ${ }^{4}$. Como expoente hobessiano, citaríamos David Gauthier. Autor de um estudo seminal sobre o Leviatã ${ }^{5}$, Gauthier ousou ser hobessiano e propôs uma moral by agreement $t^{6}$ nos moldes da filosofia política de Hobbes. De qualquer forma, estes últimos estão muito

\footnotetext{
2 Preconizada, sobretudo, pela profícua discussão entre Marsílio de Pádua e o Papa João XXII acerca do direito à propriedade, discussão na qual é estabelecida, por Marsílio de Pádua, a distinção entre ius naturale e ius positivum. Com efeito, tal discussão não passará despercebida pelos modernos, especialmente por Thomas Hobbes (que, aliás, inaugurará o contratualismo - e a filosofia política mesma - na modernidade).

3 "Meu objetivo é apresentar uma concepção de justiça que generaliza e leva a um plano superior de abstração a conhecida teoria do contrato social como se lê, digamos, em Locke, Rousseau e Kant" (RAWLS, J. Uma teoria da justiça. São Paulo: Martins Fontes, 2000).

${ }^{4}$ Ver, por exemplo: SCANLON, T.M. What we owe to each other. Cambridge: Harvard University Press, 2000. Em tal obra (na qual ele trabalhava desde 1979) o autor nos fala da 'justificabilidade' como base normativa da Moral. Assim, à questão "O que devemos uns aos outros?", Scanlon responde: devemos atos que possam ser justificados perante os demais. Ações corretas são aquelas cuja validade ninguém poderia, razoavelmente, negar.

${ }^{5}$ GAUTHIER, D. The Logic of Leviathan: The Moral and Political Theory of Thomas Hobbes. Oxford: Clarendon Press, 1969.

6 GAUTHIER, D. Morals by Agreement. Oxford: Oxford University Press, 1986. Nessa obra D. Gauthier trata de demonstrar que conceitos tais quais os de "boa vontade" são desnecessários na fundamentação da moral. Nesse sentido, o autor recorre à metáfora do prisioneiro ('dilema do prisioneiro') para sustentar a possibilidade de uma moral alicerçada em interesses particulares. Assim, D. Gauthier sustenta uma teoria normativa da moral com a pretensão de deduzir a moral de premissas não-morais da "escolha racional". Sua tese: em certas circunstâncias é racional, mesmo para o egoísta amoral, seguir uma motivação moral (com vistas ao benefício próprio). Tal concepção de moral tem como pano de fundo, pois, a idéia de um "cálculo racional" (para o ingresso em sociedade) tal como este é engendrado por T. Hobbes.
} 
mais preocupados com um contratualismo moral do que com um contratualismo político?.

Não obstante, pretendemos sustentar que um modelo de justificação (em filosofia política) cujas raízes estejam em Kant é aquele que mais se aproxima de uma idéia de Justiça. Ou, ainda, tal modelo é aquele que mais se aproximaria, segundo cremos, de uma fundamentação moral da política. E tal é a base dos modelos de Rawls e de Dworkin, apesar de todas as diferenças presentes entre ambos 8 .

\section{I}

Como é sabido, Rawls, já nos anos 50, começa a desenvolver uma concepção de Justiça por ele denominada de Justice as fairness ${ }^{9}$. Nesse sentido, já em sua tese de doutorado ${ }^{10}$ aparece a idéia de 'justificação moral', a qual servirá, posteriormente, de base para sua teoria da justiça. Assim, dir-seia que sua proximidade com os autores acima referidos (sobretudo com Kant) já era evidente ao longo dos anos 50 (seja pela sua 'cultura política pública', seja por sua pretensão de uma fundamentação moral da política mediante uma 'idéia' de Justiça as fairness). Dessa forma, desde sua forma mais embrionária, o modelo rawlsiano de fundamentação era essencialmente deontológico, o que fica expresso, sobretudo, ao início de sua "Uma Teoria da Justiça"11 (1971), onde ele critica duramente os modelos utilitaristas até então vigentes (e que até então não haviam sido confrontados de forma tão dura e devastadora).

Assim, o modelo de Rawls transforma conceitos caros à tradição contratualista de forma a torná-los inteligíveis no contexto contemporâneo.

\footnotetext{
7 Um contratualismo político, e isso é algo que está evidente especialmente em Rawls, está preocupado especialmente com as instituições políticas, sociais e econômicas.

${ }^{8}$ Ambos, Rawls e Dworkin, sustentam um 'liberalismo de princípios' de jaez kantiano. Assim, seus modelos de fundamentação não estão preocupados tão somente com a justificação de certos arranjos institucionais. Sua preocupação é legitimar (moralmente) um certo estado de direito. Aqui se manifesta, pois, uma exacerbada preocupação com a justiça.

${ }^{9}$ Expressão cunhada em 1958 em seu artigo: "Justice as fairness". In: RAWLS, J. Collected papers. Cambridge: Harvard University Press, 2001, p. 47-72. Tal concepção de justiça, a propósito, é exeqüível em uma sociedade democrática constitucional (liberal) marcada pelo fato do pluralismo (razoável) e por uma concepção normativa de pessoa moral, igual e livre.

10 Defendida em 1951, em Princeton, sua tese tinha como título: "A Study in the Grounds of Ethical Knowledge: Considered with reference to judgments on Moral worth of Character".

${ }^{11}$ RAWLS, J. Uma teoria da Justiça. São Paulo: Martins Fontes, 2000. Doravante, T.J.
} 
Dessa forma, temos a 'posição original' (original position), que, em 195812, ao ser introduzida, ainda era denominada por Rawls de 'posição geral' (general position), bem como o 'véu da ignorância' 13 (veil of ignorance) e, é claro, os princípios escolhidos em tal situação hipotética ('posição original'). Com efeito, tal estrutura garantiria a imparcialidade dos princípios escolhidos e, é claro, a justiça como eqüidade.

Tal modelo é, certamente, um dos mais significativos na tradição liberal, sendo um divisor de águas no âmbito da filosofia política: essa pode ser considerada anterior ou posterior à publicação de 'T.J.', dado que a discussão posterior estará articulada especialmente em torno da obra de Rawls (ainda que para contestá-la $)^{14}$. Tal reação inicial estará não apenas dentro daquelas correntes que de imediato se opuseram às teses de Rawls, mas mesmo dentre os simpatizantes do modelo liberal, entre os quais está Ronald Dworkin, autor cuja magnitude é equiparável à de Rawls.

Não obstante, o modelo de justificação proposto por Rawls tem, em linhas gerais, aqueles mesmos elementos já presentes nos autores modernos, especialmente a idéia de uma situação hipotética ('estado de natureza'/'posição original') e a idéia de pacto social.

Com efeito, dado o caráter político do contratualismo de Rawls, ele partirá da idéia de que pensar a justiça é refletir acerca do justo e do injusto nas instituições. Afinal, a maneira mais apropriada de administrarmos a justiça é mediante tais instituições sociais. Portanto, é a presença (ou ausên-

\footnotetext{
12 Somente em 1963 ela passa a ser chamada, por Rawls, de original position: Cf. "Constitutional liberty and the concept of justice". In: Rawls, J. Collected papers. Cambridge: Harvard University Press, 2001, p. 73-95.

${ }^{13}$ Que passa a figurar a partir do artigo de 1967 intitulado: "Distributive justice". In: RaWls, J. Collected papers. Cambridge: Harvard University Press, 2001, p. 130-153.

${ }_{14}$ Robert Nozick, notório opositor do modelo liberal (liberalism) de Rawls, em sua defesa de um "libertarianismo" (libertarianism) afirma, naquela que é a sua principal obra, bem como uma das primeiras reações a "Uma teoria da Justiça": "A theory of justice is a powerful, deep, subtle, wide-ranging, systematic work in political and moral philosophy which has not seen its like since the writings of John Stuart Mill, if then. It is fountain of illuminating ideas, integrated together into a lovely whole. Political philosophers now must either work within Rawls's theory or explain why not" (NOZICK, R. Anarchy, State, and Utopia. Basic Books, 1974, p. 183. Além do Libertarianism, poderíamos citar também, como reação quase imediata a "Uma Teoria da Justiça", o Comunitarismo que já passa a tomar forma em 1973 com Michael Walzer e sua concepção de 'justiça complexa', sendo elevado ao estatudo de corrente filosófica especialmente a partir da publicação da obra Liberalism and the limits of justice (Cambridge: Cambridge University Press, 1982), de Michael Sandel. Além desses, ainda haveria o modelo de uma fundamentação discursiva, por Jürgen Habermas, o qual também manteve (mais tarde) uma acalorada discussão com Rawls.
} 
cia) da justiça nas instituições ${ }^{15}$ sociais que beneficia (ou prejudica) a comunidade a elas vinculada, especialmente os projetos particulares (distintas concepções de bem).

Assim sendo, o fundamento normativo do contratualismo rawlsiano alicerçar-se-á sobre o conceito de 'posição original'16. Tal 'posição' permitirá a simulação ${ }^{17}$ de condições ideais de igualdade que possibilitarão a escolha de princípios válidos para todos os indivíduos que se encaixem na concepção normativa de pessoa proposta por Rawls ${ }^{18}$. Assim, a 'posição original' é o status quo inicial hipotético essencial à garantia da "justiça como eqüidade". É nessa 'posição' que sujeitos racionais escolherão os princípios que deverão nortear a fundamentação das instituições sociais. Tais princípios serão princípios de justiça, e não meros princípios prudenciais. Nela as partes 'contratantes' deliberam acerca de quais princípios poderão constituir os fundamentos de uma 'sociedade bem ordenada' (well ordered society), a qual expressa o modo pelo qual as instituições sociais, econômicas e políticas se articulam em um sistema. Com efeito, em tal sociedade vige a concepção de justiça enquanto idéia regulativa sem a qual a eqüidade não se manteria. Ligado ao conceito de 'posição original' está o de 'véu da ignorância' (veil of ignorance), com o qual Rawls pretende assegurar a imparcialidade na escolha dos princípios. Ao lado da 'posição original', o 'véu da ignorância' faz parte de uma estratégia para evitar que o indivíduo escolha princípios que venham em benefício dele mesmo e dos seus ${ }^{19}$. Tal estratégia é o procedimento mediante

\footnotetext{
${ }^{15}$ Isso porque a melhor forma de administrarmos a justiça é mediante as instituições: sociais (família...), econômicas (mercado...) e políticas (constituições...). Por essa razão podemos afirmar que o liberalismo de Rawls é (assim como o será o de Dworkin), sem dúvida alguma, intervencionista.

${ }^{16}$ Tal será, como veremos, o principal ponto de crítica por parte de Dworkin (cf. Dworkin, R. 'The original position'. In: Daniels, N. (ed). Reading Rawls. Stanford: Stanford University Press, 1975).

${ }_{17}$ Desde 0 início Rawls caracteriza tal 'posição original' como mera hipótese. Não se trata, pois, de um acordo histórico obtido faticamente. Dessa forma, a 'posição original' aparece no quadro da 'teoria ideal'* (primeira parte - $\S \S 1$ a 30 - de T.J).

${ }^{*} A$ 'teoria ideal' corresponde às duas primeiras partes de T.J (Teoria e Instituições - §§ 1 a 59 -). A parte referente à 'teoria não-ideal' estaria expressa especificamente na terceira parte (Fins - $\S \S 60$ a 87), sendo que nela Rawls tenta demonstrar que sua teoria ideal é exeqüível - realismo utópico - mediante 0 'equilíbrio reflexivo'. Tal divisão marca, sobretudo, o caráter deontológico do modelo rawlsiano: primeiro tratamos do dever ser para, então, tratarmos do ser.

${ }_{18}$ Tal pessoa é racional, igual e livre (além de possuir duas capacidades morais: a capacidade de formular uma concepção de bem - racional - e a capacidade de agir segundo princípios de justiça razoável). Sobre tal ponto ler: OLIVEIRA, N. F. 'A concepção normativa de pessoa e sociedade em Kant e Rawls: Uma interpretação semântico-transcendental'. Dissertatio, Pelotas, n.24, p. 23-40, verão de 2006.

${ }^{19}$ Para evitar aquela concepção de justiça presente, por exemplo, no discurso de Trasímaco na já citada "República", de Platão. Com efeito, como é sabido, o sofista Trasímaco mantém que a justiça é o "inte-
} 
o qual podemos justificar/legitimar a 'estrutura básica' da 'sociedade bem ordenada'. Nas palavras de Rawls:

$\mathrm{Na}$ justiça como eqüidade a posição original de igualdade corresponde ao estado de natureza na teoria tradicional do contrato social. Essa posição original não é, obviamente, concebida como uma situação real histórica, muito menos como uma condição primitiva da cultura. É entendida como uma situação puramente hipotética caracterizada de modo a conduzir a uma certa concepção de justiça (Rawls, J. T.J., p. 13. Grifo nosso)

De algum modo, devemos anular os efeitos das contingências específicas que colocam os homens em posições de disputa, tentando-os a explorar as circunstâncias naturais e sociais em seu próprio benefício. Com esse propósito, assumo que as partes se situam atrás de um véu da ignorância. Elas não sabem como as várias alternativas irão afetar o seu caso particular, e são obrigadas a avaliar os princípios unicamente com base nas considerações gerais (Rawls, J. T.J, p. 147. Grifo nosso).

Com o procedimento acima esboçado, Rawls logra estabelecer princípios cujo valor é universal, bem como a autonomia dos pactuantes. Ou, ainda, fica resguardada a concepção normativa de pessoa livre, igual e racional. Não apenas isso, tal estratégia garantiria que não surgiriam acordos e alianças com vistas ao privilégio de pequenos grupos. Dessa forma, o 'véu da ignorância' cobre a história particular de cada um dos indivíduos na 'posição original', permitindo que sejam escolhidos princípios cujo valor é universal ${ }^{20}$. Dessa forma,

resse do mais forte": afinal, é este quem escolhe as leis, de tal forma que estas sempre vêm em benefício dele e dos seus. Nas palavras do sofista: "Eis, portanto, excelentíssimo, o que eu digo ser justo sempre, em todas as cidades sem exceção: o vantajoso para o governo estabelecido. É ele que tem 0 poder e, para quem raciocina corretamente, em todos os lugares, o justo é sempre a mesma coisa, a vantagem do mais forte" (República, 339 a, p.20). De qualquer maneira, na 'posição original', sob o 'véu da ignorância', os contratantes desconhecem todos aqueles elementos que os situam em determinada esfera social: status social, habilidades, sua própria concepção de bem (do que é estimável enquanto projeto de vida), etc. Este é o artifício procedimental do qual Rawls lança mão para garantir a primazia do justo sobre o bem em um modelo deontológico de raiz evidentemente kantiana.

${ }^{20}$ No horizonte de sujeitos racionais, iguais e livres. 
A posição original é definida de modo a ser um status quo no qual qualquer consenso atingido é justo. É um estado de coisas no qual as partes são igualmente representadas como pessoas dignas, e o resultado não é condicionado por contingências arbitrárias ou pelo equilíbrio relativo das forças sociais (Rawls, j. T.J. p. 129).

Portanto, a justiça as fairness não é um 'doutrina compreensiva'21, muito embora se apóie em elementos oriundos de algumas delas. Ela é uma freestanding view, o que lhe garante a imparcialidade.

Pois bem, agora cabe a questão: Que princípios são escolhidos na 'posição original', sob o 'véu da ignorância'?

São dois os princípios escolhidos. O primeiro é o 'princípio da igual liberdade' (equal liberty principle), o qual concerne aos direitos fundamentais: propriedade, renda, consciência, religião, participação política, pensamento, desobediência civil, etc. Tal princípio estabelece as "liberdades básicas":

É essencial observar que é possível determinar uma lista dessas liberdades. As mais importantes entre elas são a liberdade política (o direito de votar e ocupar um cargo público) e a liberdade de expressão e reunião; a liberdade de consciência e de pensamento; as liberdades da pessoa (...); o direito à propriedade privada e a proteção contra a prisão e a detenção arbitrárias (...). Segundo o primeiro princípio, essas liberdades devem ser iguais (Rawls, J. T.J. p.65. Grifo nosso).

Aqui Rawls expressa seu mais profundo vínculo com o modelo liberal proposto por John Locke ${ }^{22}$, bem como com o impacto do pensamento deste na revolução norte-americana. Nesse primeiro momento são escolhidos os direitos individuais de base, os quais estado algum pode violar ${ }^{23}$.

21 'Doutrinas compreensivas' (compreensive doctrines) são modos particulares de vida, os quais devem estar circunscritos a uma concepção política de justiça. São as concepções particulares de vida, os valores adotados, etc. Dizem respeito às concepções religiosas, filosóficas, etc. Em geral elas estão enraizadas em uma determinada tradição cultural. Por essa razão elas podem ser consideradas enquanto culturas de fundo das sociedades civis. Elas podem ser razoáveis (permissíveis) ou nãorazoáveis (não-permissíveis).

22 Especialmente a partir do Second Treatise of Government, de 1690, e da presença das idéias expressas neste na Revolução Americana de 1776.

${ }^{23} \mathrm{Nem}$ mesmo com vistas ao benefício do maior número, como propõe o utilitarismo. 
Com efeito, o primeiro princípio é apresentado em dois momentos de T.J. ${ }^{24}$ e estabelece que "Cada pessoa deve ter um direito igual ao mais abrangente sistema de liberdades básicas iguais que seja compatível com um sistema semelhante de liberdade para as outras (Rawls, T.J. p.64).

O segundo princípio, por seu turno, assegura a partilha equitativa dos bens primários estabelecidos pelo primeiro princípio. Tal é o 'princípio da diferença' (difference principle). Não apenas isso, tal princípio também regula os interesses materiais, propondo, por exemplo, políticas redistributivas ${ }^{25}$. Assim, aqui Rawls toma emprestado da Economia o conceito de maximin (maximum minimorum), ou seja, de maximização do (ganho) mínimo ${ }^{26}$. E é aqui, com efeito, que entra a principal crítica "libertária" a Rawls, dado que tal princípio autoriza a intervenção estatal para garantir que não prevalecerá a "loteria natural" (natural lottery). Afinal, esta é totalmente arbitrária, dado que ninguém escolhe nascer em certa classe, dotado de determinada incapacidade, sem habilidade para atividades estimadas (e "rentáveis") socialmente, etc. dessa forma, tal princípio torna inadmissível (injusto) o laissez- faire do libertarianismo (Libertarianism) ${ }^{27}$. Assim, o 'princípio da diferença' regula a distribuição de bens primários (primary goods) ${ }^{28}$. Por essa razão, ligado ao 'princípio da diferença' está o 'princípio da igualdade eqüitativa de oportunidades' (fair equality of opportunities). $\mathrm{Na}$ definição de Rawls do segundo princípio:

As desigualdades sociais e econômicas devem ser ordenadas de tal modo que sejam ao mesmo tempo (a) consideradas como vantajosas para todos dentro dos limites do razoável, e (b)

\footnotetext{
${ }^{24}$ Cf. Rawls, T.J. 2000, p.64 e p.333.

${ }^{25}$ Nesse sentido, ver, por exemplo, os trabalhos de Philippe Van Parijs e a idéia de uma "basic income" enquanto tentativa de estabelecer um "egalitarian capitalism". Aqui sobressai-se uma concepção de justiça distributiva (proporção geométrica), e não de justiça comutativa (proporção aritmética).

${ }_{26} \mathrm{Ou}$, ainda, de minimização das perdas (daí ele também ser conhecido como minimax - minimizar a perda máxima possível -).

${ }^{27}$ Preconizado por Adam Smith (com sua idéia de uma invisible hand) e posteriormente solidificado nas posições de autores tais quais F. Hayek e R. Nozick.

${ }^{28}$ Há bens primários naturais (saúde, inteligência, talentos, etc.) e bens primários sociais (distribuídos pelas instituições sociais), sendo que mesmo os primeiros são afetados pelas instituições (embora não sejam por elas distribuídos)
} 
vinculadas a posições e cargos acessíveis a todos (Rawls, J. T.J. 2000, p.64).

Mais adiante (p.333), ele o reformula:

As desigualdades econômicas e sociais devem ser ordenadas de tal modo que, ao mesmo tempo:

(a) tragam o maior benefício possível para os menos favorecidos, obedecendo às restrições do princípio da poupança justa, e

(b) sejam vinculadas a cargos e posições abertos a todos em condições de igualdade eqüitativa de oportunidades ${ }^{29}$.

Em suma, tais princípios são escalonados consoante uma ordem lexical: (1) princípio da igual liberdade, (2) princípio da igualdade eqüitativa de oportunidades e (3) princípio da diferença. Além disso, eles não são dirigidos a indivíduos, mas às instituições, uma vez que são estas que regulam a vida social e, digamos, o "destino" dos indivíduos ${ }^{30}$. Assim sendo, as instituições devem garantir a todos aqueles 'bens primários' 31 socialmente (publicamente) reconhecidos como necessários para que o indivíduo consolide sua autoestima e, assim, atinja sua concepção de bem (conception of the good), isto é, seu projeto particular de vida. Tal momento seria o primeiro (o da escolha dos princípios). Posteriormente, outros momentos (constitucional, legislativo e judiciário) consolidariam a implementação de tais princípios, constituindo, dessa maneira, a 'sociedade bem-ordenada'.

\footnotetext{
29 Isso significa dizer que todos terão a oportunidade de alcançar tais cargos (obviamente eles não estarão disponíveis a todos). 0 critério de ascensão é a competência publicamente reconhecida. Por essa razão, estabelece o 'princípio da diferença' que, "tomando a igualdade como base de comparação, aqueles que ganharam mais devem tê-lo feito em termos que são justificáveis aos olhos daqueles que ganharam o mínimo" (Rawls, J. T.J. 2000, p.163). Isso também envolve a idéia de 'cidadão razoável', ou seja, aquele que vê o outro como igual e livre, aceitando certas regras de cooperação social (a isto Rawls denomina "critério de reciprocidade"). Aqui temos uma espécie de "meritocracia eqüitativa".

30 "A justiça é a primeira virtude das instituições sociais, como a verdade o é dos sistemas do pensamento. Embora elegante e econômica, uma teoria deve ser rejeitada ou revisada se não é verdadeira; da mesma forma leis e instituições, por mais eficientes e bem organizadas que sejam, devem ser reformadas ou abolidas se são injustas" (Rawls, J. T.J. 2000, p.4-5).

${ }^{31}$ Tais quais saúde, educação, uma renda, segurança.....
} 


\section{II}

À guisa de conclusão do que vimos acima, podemos dizer que a partir da posição original, notadamente dos princípios nela escolhidos (dentro do quadro procedimental explicitado), a história de uma dada sociedade passa a ser (re)escrita: $A$ partir dos princípios (tendo-os como pano de fundo ${ }^{32}$ ) é estabelecida uma constituição, sendo que a partir desta são promulgadas leis que serão, no âmbito judiciário, resguardadas (zelar-se-á pela sua aplicação à luz dos princípios).

Como foi demonstrado acima, a escolha dos princípios se dá em uma situação especial meramente "imaginada": a 'posição original' é uma abstração utilizada como critério procedimental-deontológico para a escolha de princípios que possam atender às exigências da concepção de uma 'justiça como eqüidade'.

Pois bem. Além de toda a crítica imediata que tal concepção suscitou em autores tais quais Robert Nozick (libertarianism) e Michael Walzer (comunitarismo), as críticas também vieram celeremente de autores liberais, sendo que aqui nos importa aquele que, como dito anteriormente, possui a mesma envergadura filosófica de Rawls, a saber, Ronald Dworkin.

Assim, na primavera de 1973, na University of Chicago Review, Dworkin publica o artigo intitulado "The Original Position", no qual repousam suas primeiras críticas ao modelo neocontratualista de Rawls ${ }^{33}$. Com efeito, sua crítica estará direcionada para um conceito basilar: o de 'posição original'. Dworkin reconhece no conceito de 'posição original' uma premissa de descoberta dos princípios propostos por Rawls. Não obstante sua crítica a Rawls, Dworkin vai sustentar um modelo muito semelhante ao contratualista, com o qual ele obviamente simpatiza ${ }^{34}$. Todavia, pelas razões que elencaremos abaixo ele se auto-desvincula deste grupo.

Sendo assim, após se eximir por não expor detalhadamente a concepção de Justice as Fairness de Rawls, Dworkin sintetiza os princípios esco-

\footnotetext{
${ }^{32}$ E tendo a 'posição original' como premissa de descoberta de tais princípios.

${ }^{33}$ Cf. DWORKIN, R. "The Original Position", University of Chicago Review, V.40, n. 3, p.500-533, 1973.

Publicado novamente em: Daniels, N. (ed). Reading Rawls. Stanford: Stanford University Press, 1975, p. 16-52. Com efeito, tal texto ainda aparecerá em 1977 em seu Levando os direitos a sério (Dworkin, R. Levando os direitos a sério. São Paulo: Martins Fontes: 2002, Cap.VI).

${ }^{34}$ Até porque ele, tal como Rawls, é fortemente influenciado por autores tais quais Rousseau, Locke e Kant.
} 
lhidos na 'posição original'35 e apresenta algumas críticas que poderiam ser levantadas contra Rawls, as quais não são todas exatamente suas (e algumas das quais ele próprio não aprofunda). A primeira afirma que Rawls não considera a possibilidade de que "jogadores" (Gamblers) ${ }^{36}$ estejam na 'posição original'. Ora, jogadores arriscariam e escolheriam princípios diferentes (mesmo estando sob o 'véu da ignorância'), haja vista que "arriscar" faz parte da natureza do jogador. Dessa forma, os princípios estabelecidos por Rawls seriam escolhidos, segundo Dworkin, por conservadores. De qualquer maneira, a fragilidade de tal crítica surge (e isso é algo que Dworkin não evidencia, dado que ele próprio não está interessado em explorar tal crítica) quando consideramos que Rawls parte de uma concepção normativa de pessoa ${ }^{37}$. Assim, a pessoa, tal como a concebe Rawls ${ }^{38}$ - igual, livre, racional.....-, escolheria, inquestionavelmente, tais princípios. Portanto, tal pessoa estaria pressuposta na 'posição original'. Outra crítica (esta, sim, interessa a Dworkin) concerne ao fato de que o contrato, em Rawls, é hipotético ${ }^{39}$. Ora, um contrato hipotético não seria nem mesmo um contrato. $\mathrm{O}$ exemplo dado por Dworkin para enfatizar a fragilidade da idéia de contrato é o seguinte: suponhamos que estejamos jogando um certo jogo. É possível que, se houvéssemos sido consultados antes, concordássemos com certas regras fundamentais desse jogo. Mas isso não significa, conforme Dworkin, que tais regras possam ser usadas contra nós caso discordemos delas. Certamente, haveria razões para que concordássemos com elas, sendo que tais razões expressariam o por que de elas serem usadas contra nós caso não as aceitássemos. Todavia, nossa

\footnotetext{
35 "These provide, roughly, that every person must have the largest political liberty compatible with a like liberty for all, and that inequalities in power, wealth, income, and other resources must not exist except in so far as they work to the absolute benefit of the worst members of society" (DWORKIN, R. "The original Position". In: Daniels, N. (ed). Reading Rawls. Stanford: Stanford University Press, 1975, p.17).

36 "Os princípios são moderados, e os críticos acreditam que só seriam escolhidos por pessoas de temperamento cauteloso, e não por pessoas que fossem apostadoras natas" (Dworkin, R. Levando os direitos a sério. São Paulo: Martins Fontes, 2002).

37 Ver nota 18.

${ }^{38}$ Dessa forma, uma tal crítica demandaria uma revisão de sua concepção de pessoa - ou sua rejeição - , o que é feito especialmente pelos Comunitaristas. Ver, por exemplo, Michael Sandel e sua obra "Liberalism and the Limits of Justice" (Cambridge: Cambridge University Press, 1982), na qual temos uma das mais perspicazes críticas ao Liberalismo.

39 "Hypothetical contracts do not supply an independent argument for the fairness of enforcing their terms. A hypothetical contract is not simply a pale form of an actual contract; it is no contract at all" (DWORKIN, R. "The original Position". In: Daniels, N. (ed). Reading Rawls. Stanford: Stanford University Press, 1975, p.17-18).
} 
hipotética anuência não contaria como uma razão ${ }^{40}$. E esse é, na perspectiva de Dworkin, um dos principais problemas da 'posição original': segundo ela, devemos acatar princípios escolhidos em uma situação muito diferente da atual. Ou seja: aceitamos que princípios escolhidos em uma situação hipotética determinem a situação atual/ $/$ real $^{41}$.

De qualquer forma, cabe ressalvar que há mais semelhanças entre Rawls e Dworkin do que diferenças. O ponto central da, digamos, desavença, é a idéia de 'posição original', a qual Dworkin realmente não aceita. Seu modelo reluta em ser contratualista, muito embora pareça vermos nele um certo contratualismo mitigado. Em verdade, o texto de Dworkin acentua também a proximidade entre seu modelo e o modelo de Rawls. Assim, ele refuta, por exemplo, a leitura que Hare ${ }^{42}$ faz de Rawls. Segundo Dworkin, Hare coloca Rawls dentro de um modelo que ele denomina de "modelo natural” (Natural model), o qual pressupõe uma ontologia moral. Assim, no quadro de tal "modelo natural" os princípios não são criados, mas descobertos (assim como são descobertas, por exemplo, as leis da física). Com efeito, tal descoberta serviria para produzir intuições de moralidade política em situações particulares. Esta seria uma das perspectivas a partir das quais uma teoria da justiça poderia ser desenvolvida. A outra é o "modelo construtivista” (Constructive model). Este modelo vê as intuições de um ponto de vista público: aqui se propõe uma concepção de justiça para uma comunidade na qual os indivíduos têm convicções distintas.

Conforme Dworkin, o modelo de Rawls (tal como o seu) se enquadraria exatamente dentro deste último (Constructive), o que é evidenciado pela idéia de "equilíbrio reflexivo" (reflexive equilibrium). Ora, um "equilíbrio

\footnotetext{
${ }^{40}$ Nos termos de Dworkin: "A judgment of antecedent interest depends upon the circumstances under which the judgment is made, and, in particular, upon the knowledge available to the man making the judgment" . Ou: "the fact, therefore, that a particular choice is in my interest at a particular time, under conditions of great uncertainty, is not a good argument for the fairness of enforcing that choice against me later under conditions of much great knowledge" (DWORKIN, R. "The original Position". In: Daniels, N. (ed). Reading Rawls. Stanford: Stanford University Press, 1975, p.20).

41 "A escolha dos dois princípios não é do melhor interesse atual de cada um, pois, ao levantar-se 0 véu da ignorância, alguns irão descobrir que estariam numa situação melhor se tivessem escolhido algum outro princípio (...). Um juízo de interesse antecedente depende das circunstâncias nas quais é feito e, em particular, do conhecimento disponível àquele que julga. Poderia ser de meu interesse antecedente apostar, com certa probabilidade de ganhar, em um determinado cavalo antes do tiro de partida, mas não, pelo menos com a mesma probabilidade, depois que ele tiver tropeçado na primeira volta" (Dworkin, R. Levando os direitos a sério. São Paulo: Martins Fontes, 2005, p. 239)..

42 HARE, R.M. "Rawls' Theory of Justice". In: Daniels, N. (ed). Reading Rawls. Stanford: Stanford University Press, 1975, p. 81-107.
} 
reflexivo"43 só faz sentido no quadro de um "modelo construtivista". Como nos diz Dworkin, tal modelo é de "vai e volta": ajustes na teoria e ajustes nas convicções de cada um. Assim, a técnica do equilíbrio (equilibrium technique) "produz princípios que são relativos em ao menos dois sentidos. Primeiro, ela é projetada para selecionar a melhor teoria da justiça de uma lista de teorias alternativas as quais não são apenas finitas, mas breves o suficiente para que possam ser feitas comparações entre elas" (...). "Em segundo lugar, ela dá resultados que são relativos à área de acordo inicial entre aqueles que colegiadamente conduzem os experimentos especulativos que ela recomenda. Ela é projetada, como diz Rawls, para conciliar sujeitos discordantes ao fixar o que é comum entre eles" ${ }^{4}$. Dessa forma, para usarmos da metáfora de Dworkin, no caso do modelo construtivista é "como se um escultor se colocasse a esculpir o animal que melhor servisse na pilha de ossos que porventura se encontrasse" 45 ; portanto, podemos dizer que o animal que se encaixa nos ossos do exemplo acima não existe necessariamente ${ }^{46}$.

\section{III}

The two principles comprise a theory of justice that is built up from the hypothesis of a contract (...). It must be seen as a kind of halfway point in a larger argument, as itself the product of a deeper political theory that argues for the two principles through rather than from the contract ${ }^{47}$.

A citação acima não apenas aponta para aquela já sugerida diferença entre Rawls e Dworkin no tocante à fundamentação de uma concepção de justiça, mas também deixa clara a proximidade de Dworkin do modelo contratualista.

Com efeito, o primeiro ponto a ser enfatizado quanto à teoria da justiça de Dworkin é o seguinte: há um princípio ainda mais fundamental do que aqueles propostos por Rawls, qual seja: o da "igual consideração e respeito" (equal concern and respect). Além disso, Rawls fundamenta seus princípios 'a partir' (from) do contrato (tais princípios seriam, por assim dizer,

\footnotetext{
${ }^{43} \mathrm{O}$ "equilíbrio reflexivo" é a forma mediante a qual os princípios vão sendo objetivados em uma sociedade pluralista

${ }^{44}$ DWORKIN, R. "The original Position". In: Daniels, N. (ed). Reading Rawls. Stanford: Stanford University Press, 1975, p.34-35).

45 Idem, , p.28.

${ }^{46}$ No "modelo natural" ele existiria necessariamente.

${ }^{47}$ DWORKIN, R. Op. cit., p.37 (grifo nosso).
} 
“engendrados” na 'posição original'). Dworkin, por seu turno, fundamentaria os princípios 'mediante' (through) uma situação semelhante à contratual. Esta não seria, segundo Dworkin, a premissa de descoberta dos princípios. Aliás, é digno de nota que Dworkin não nega uma situação inicial. O que ele nega é que tal situação seja uma premissa primeira a partir da qual são engendrados os princípios.

De qualquer forma, Dworkin partirá de alguns pressupostos os quais já estão em Rawls. Em primeiro lugar, ele também estará preocupado em estabelecer uma concepção de justiça exeqüível em uma sociedade caracterizada pelo pluralismo, especialmente pela variedade de 'concepções de bem'. Nele também encontramos dois pressupostos fundamentais: 1) crença na dignidade humana e 2) crença na igualdade política ${ }^{48}$. Todas as desigualdades, também segundo Dworkin, devem estar relacionadas com as escolhas livres feitas ao longo da vida (devem ser oriundas destas). O estado deve ser, pois, "sensível à ambição" (Ambition-sensitivity: igualar as circunstâncias) e "insensível à dotação" (Endowment-insensitivity: ignorar 'bens naturais' desiguais). Em suma, o destino dos indivíduos deve ser determinado pelas escolhas que eles fazem a partir de um ponto de partida justo e equitativo. Aliás, aqui reside o cerne da crítica de Dworkin a Rawls: O modelo de Rawls não seria, conforme Dworkin, "insensível à dotação"49. Afinal, o sujeito, na 'posição original', desconhece suas particularidades (a ausência de um talento para alcançar riqueza, por exemplo). Assim, ele deverá estar consciente de suas particularidades, segundo Dworkin, pois assim ele poderá levá-las em conta por ocasião de suas deliberações em tal situação inicial de igualdade.

Nesse sentido, chegamos agora à questão: Como Dworkin fundamenta sua concepção de Estado?

Pois bem. O ponto de partida será aquela virtude por ele denominada de "virtude soberana" (Sovereign virtue), a saber, o já mencionado princípio da "igual consideração e respeito", isto é, a "consideração igualitária pelo

\footnotetext{
${ }^{48}$ Além disso, tanto para Rawls quanto para Dworkin o homem possui direitos cujo valor é intrínseco: à vida, à liberdade (de expressão, associação....), etc. Temos em ambos, também, diversos valores fundamentais: direitos civis, liberdades políticas, igualdade de bens primários, autonomia individual, igualdade equitativa de oportunidades, justiça distributiva, etc.

${ }^{49}$ Conforme Dworkin, o 'princípio da diferença' não leva suficientemente em conta as diferenças interpessoais de preferências, gostos, ambições, etc. Nesse sentido, fica evidente que Dworkin pretende, de uma certa forma, aperfeiçoar a teoria de Rawls. Assim, para compensar a deficiência das habilidades de determinados indivíduos, Dworkin propõe uma espécie de mecanismo de seguro (utilizaríamos uma porção de nossas conchas em um seguro para precaver-nos contra possíveis infortúnios oriundos de nossas particularidades (uma incapacidade para atividades rentáveis, por exemplo).
} 
destino de todos os cidadãos sobre os quais o governo afirma seu domínio" ${ }^{50}$. Ou, ainda: "Todas as pessoas e seus planos de vida devem ser tratados com igual consideração e respeito". Em resumo: “A consideração igualitária é a virtude soberana da comunidade política" 51 .

Com efeito, Dworkin parte, em sua busca de uma concepção inicial de igualdade, de duas acepções distintas: igualdade de bem estar e igualdade de recursos. Quanto à igualdade de bem estar, Dworkin afirma que esta não poderá ser o ponto de partida de sua teoria da justiça: afinal, cada um "tem idéias próprias sobre o que torna a vida melhor, sobre onde está seu próprio bem estar essencial" 52 . Ou seja, cada um faz suas escolhas sem levar em conta o custo que isto representará para os outros. Em resumo, nos termos de Dworkin:

$\mathrm{Na}$ igualdade de bem-estar, as pessoas devem decidir que tipo de vida querem, independentemente das informações pertinentes para decidir o quanto suas escolhas reduzirão ou aumentarão a capacidade de outros terem o que querem ${ }^{53}$.

Assim, dado que não podemos tomar a idéia de uma igualdade de bem-estar como ponto de partida, Dworkin tenta, então, ver da possibilidade de usarmos da "igualdade de recursos". Esta será, com efeito, a que mais se aproximará da concepção de justiça perseguida por Dworkin. Segundo ele:

A igualdade de recursos, por outro lado, oferece uma definição da igualdade distributiva imediata e obviamente sensível ao caráter especial e à importância da liberdade. Ela faz com que a distribuição igualitária não dependa exclusivamente dos resultados que possam ser avaliados de maneira direta, como preferência - satisfação, mas em um processo de decisões coordenadas no qual as pessoas que assumem responsabilidade por suas próprias aspirações e projetos, e que aceitam, como parte dessa responsabilidade, que pertencem a uma comuni-

50 DWORKIN, R. Levando os direitos a sério. São Paulo: Martins Fontes, 2002, p. 419.

51 DWORKIN, R. Virtude soberana. São Paulo: Martins Fontes, 2005, p. IX. Deve-se enfatizar que a igualdade é quanto à consideração e respeito: obviamente haverá desigualdade econômica - uns terão mais do que outros -, mas esta será o resultado da escolha individual (consciente) de cada um.

52 Idem, p. 57.

53/dem, p. 85. 
dade de igual consideração, possam identificar o verdadeiro preço de seus planos para as outras pessoas e, assim, elaborar e reelaborar esses planos de modo que utilizem somente sua justa parcela dos recursos em princípio disponíveis para todos..$^{54}$

Com efeito, tal igualdade de recursos é mais apropriadamente compreendida a partir de outro conceito basilar no conjunto da fundamentação da justiça em Dworkin, a saber: o de "leilão" (auction). Tal "leilão" proporciona um

padrão para julgar instituições e distribuições no mundo real (...). O mecanismo do leilão poderia proporcionar, em outras palavras, um padrão para se julgar até que ponto uma distribuição real, qualquer que tenha sido o modo de se chegar a ela, aproxima-se da igualdade de recursos em dado momento $^{55}$.

De qualquer forma, evidencia-se o jaez procedimental do 'leilão', dado que o mesmo é, tal como a 'posição original' em Rawls, um dispositivo fictício que serve para uma avaliação das instituições, mercados e sociedades (a forma como se articulam) existentes. Ele é, então, uma metáfora ${ }^{56}$ na qual os recursos são divididos de forma equitativa. Em linhas gerais, a metáfora do 'leilão' é proposta da seguinte maneira: imaginemos náufragos em uma ilha deserta. Em tal situação eles terão que determinar um critério para a partilha igualitária de tudo o que faz parte da ilha. Que critério poderia ser este?

Ora, conforme Dworkin, o procedimento que com mais justiça poderia ser aplicado é este: determinar-se-ia que as conchas (cujo valor intrínseco é nulo) disponíveis na ilha seriam divididas de forma igual (igualdade de recursos) e utilizadas em um 'leilão' cujo princípio seria o seguinte: todos "aceitam o princípio de que ninguém tem direito prévio a nenhum dos recursos, mas que devem ser divididos igualmente entre todos" ${ }^{57}$. Assim, em um tal 'leilão' cada habitante da ilha poderia dar "lances" por aquilo que

\footnotetext{
54 Idem p. 160.

55 Idem, p. 89.

56 "É claro que nenhuma sociedade orgânica complexa teria, em sua história, nada remotamente comparável a um leilão igualitário" (Dworkin, R. Idem, p. 89).

${ }^{57}$ Idem, p. 81.
} 
julgasse importante. Em resumo, haveria um ponto de partida no qual todos estariam em uma absoluta igualdade de recursos (todos disporiam do mesmo número de conchas), de tal forma que poderiam ir aumentando gradativamente seus lances proporcionalmente ao valor que determinado objeto tivesse para ele. Em suma, qualquer objeto poderia ser de qualquer um: o que mais desejasse tal objeto daria o maior lance. Assim, ligado ao 'leilão' está o 'teste de cobiça'. Tal teste serviria para avaliar o leilão. Ou seja, se após o leilão persistisse a cobiça (pelo objeto arrematado por outro habitante), então o 'leilão' deveria ser realizado novamente. Afinal, "nenhuma divisão de recursos será uma divisão igualitária se depois de feita a divisão, qualquer um preferir o quinhão de outrem a seu próprio quinhão"58. Temos, aqui, também, o "princípio da abstração ${ }^{59}$ ". Este seria a "ponte" entre o 'teste de cobiça' e os planos individuais

Desta feita, poderíamos elencar três pontos fundamentais da metáfora do 'leilão': 1) ele impõe o respeito à igualdade moral das pessoas; 2) ele pretende minimizar os efeitos das desvantagens que são arbitrárias em uma perspectiva moral; 3) ele nos impõe que aceitemos a responsabilidade pelas nossas escolhas.

Portanto, com tal metáfora, Dworkin intenta conciliar liberdade e igualdade em um "liberalismo igualitário" que exige que todos os indivíduos desfrutem de um conjunto de direitos e liberdades ${ }^{60}$. Aliás, não apenas isso há, também, a exigência de que o governo amenize as desigualdades oriundas

\footnotetext{
58 DWORKIN, R. Virtude soberana. São Paulo: Martins Fontes, 2005, p. 81.

59 "Esse princípio define um forte pressuposto a favor da liberdade de escolha. Insiste que a distribuição ideal só é possível quando as pessoas estão legalmente livres para agir como desejarem, a não ser quando há necessidade de restrições à liberdade para proteger a segurança e a propriedade das pessoas, ou corrigir certas imperfeições dos mercados." (DWORKIN, R. Virtude soberana. São Paulo: Martins Fontes, 2005, p. 200). Em suma, com tal princípio há uma defesa da liberdade escolha: "Assim, 0 princípio da abstração insiste que as pessoas deveriam, em princípio, estar livres, no sistema paramétrico, para utilizar os recursos que adquirem, inclusive o lazer que proporcionam e protegem, por meio do programa de lances, do modo como desejarem, de maneira compatível com o princípio da segurança" (Idem, p. 206-207).

60 Dworkin, tal como Rawls, tem como pano de fundo o constitucionalismo que emerge especialmente com a Bill of Rights*(1688), com a Declaração da independência dos U.S** (1776) e com a Declaração dos Direitos do Homem e do Cidadão*** (1789).

* Revolução inglesa.

${ }^{* *}$ Revolução norte-americana.

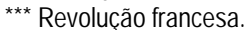

Com efeito, em tais "cartas" surgem questões tais quais: jusnaturalismo, defesa dos valores humanistas, crença no poder da razão, defesa dos direitos fundamentais inerentes à condição humana, limitação do estado, garantia dos direitos individuais, etc.
} 
de distribuições desiguais e falhas do mercado. Assim, far-se-ia necessária a implementação de políticas redistributivas. Em suma, a máxima do "liberalismo igualitário" é: os membros da sociedade devem ser tratados com igual consideração e respeito. Tal princípio, não obstante, não advém do 'leilão': ele já está dado quando do 'leilão' e é legitimado mediante este.

Todavia, Dworkin coloca questão: "o que significa para o governo tratar os cidadãos como iguais?"

E ele mesmo responde:

Essa questão, penso, é igual à questão do que significa para o governo tratar todos os cidadãos como livres, como independentes e com igual dignidade (...). Cada pessoa segue uma concepção mais ou menos articulada do que dá valor à vida. O estudioso que valoriza uma vida de contemplação tem tal concepção, assim também como o cidadão que vê televisão e bebe cerveja e gosta de dizer "a vida é assim", embora tenha pensado menos sobre a questão e seja menos capaz de descrever ou defender sua concepção (...). O bom governo consiste em tratar cada pessoa como se ela desejasse levar a vida que de fato é boa, pelo menos na medida do possível ${ }^{61}$.

Portanto, o indivíduo e seu projeto de vida (concepção de bem) devem ser tratados com igual consideração e respeito:

Presumo que todos aceitamos os seguintes postulados de moral política. O governo deve tratar aqueles a quem governa com consideração, isto é, como seres humanos capazes de sofrimento e de frustração, e com respeito, isto é, como seres humanos capazes de formar concepções inteligentes sobre o modo como suas vidas devem ser vividas, e de agir de acordo com elas. O governo deve não apenas tratar as pessoas com consideração e respeito, mas com igual consideração e igual respeito. Não deve distribuir bens ou oportunidades de maneira desigual, com base no pressuposto de que alguns cidadãos têm direito a mais, por serem merecedores de maior con-

${ }^{61}$ DWORKIN, R. Uma questão de princípio. São Paulo: Martins Fontes, 2005, p. 285-286. 
sideração. O governo não deve restringir a liberdade, partindo do pressuposto de que a concepção de um cidadão sobre a forma de vida mais adequada para um grupo é mais nobre ou superior do que a de outro cidadão. ${ }^{62}$

Dessa maneira, a hipótese do leilão parte de um princípio já dado: o da igual consideração e respeito. Com tal metáfora Dworkin parece conseguir conciliar dois conceitos caros ao pensamento liberal: igualdade e liberdade. Aliás, não seria exagero afirmar que esse é um dos principais problemas tratados na teoria da justiça de Dworkin. Todavia, não se trata, aqui, de uma igualdade absoluta. Afinal, "a igualdade absoluta e indiscriminada não é apenas um valor político fraco (...). Não é de modo algum um valor"63.

Assim, o problema é colocado por Dworkin nos seguintes termos:

Podemos dar as costas à igualdade? Nenhum governo é legítimo a menos que demonstre igual consideração pelo destino de todos os cidadãos sobre os quais afirme seu domínio e aos quais reivindique fidelidade. A consideração igualitária é a virtude soberana da comunidade política - sem ela o governo não passa de tirania - e, quando as riquezas da nação são distribuídas de maneira muito desigual, como o são as riquezas de nações muito prósperas, então sua igual consideração é suspeita, pois a distribuição das riquezas é produto de uma ordem jurídica: a riqueza do cidadão depende muito das leis promulgadas em sua comunidade - não só as leis que governam a propriedade, o roubo, os contratos e os delitos, mas suas leis de previdência social, fiscais, de direitos políticos, de regulamentação ambiental e de praticamente tudo o mais (...). Nas democracias prósperas, é previsível, sempre que o governo restringe os programas de previdência social, ou recusa a ampliá-los, que tal decisão deteriore a vida dos pobres ${ }^{64}$

Pelas passagens acima percebemos que Dworkin não aceita, portanto, a 'teoria da linha de largada': "A teoria da linha de largada afirma que a

\footnotetext{
62 DWORKIN, R. Levando os direitos a sério. São Paulo: Martins Fontes, 2002. p. 419.

${ }^{63}$ DWORKIN, R. Virtude soberana, p. X.

${ }^{64}$ Idem, p. IX-X.
} 
justiça requer recursos iniciais iguais. Mas também afirma que a justiça requer laissez-faire a partir de então"65.

Assim, Dworkin concorda com a primeira parte da proposição acima. Mas não com a segunda. Por essa razão, ele sustenta (com vistas à igualdade) a intervenção do Estado para garantir que todos serão tratados com igual consideração e respeito. Isso se justifica porque a redistribuição se faz necessária "quando a riqueza se torna assimétrica porque os talentos produtivos das pessoas são diferentes" 66 .

Mesmo que a metáfora do leilão fale de uma distribuição inicial igual, há a necessidade de, por assim dizer, dois momentos: o momento em que se igualam os indivíduos (na distribuição dos 'bens primários') e o momento em que as desigualdades vindouras inevitáveis são reparadas. Dworkin se preocupa sobremaneira com essas duas etapas de sua concepção de justiça. Trata-se da idéia de que uma concepção de justiça que pretenda aproximar igualdade e liberdade deve ser "sensível à ambição" e "insensível à dotação". Aliás, em uma de suas críticas a Rawls, Dworkin sustenta que o modelo de Rawls não daria a devida atenção a este último elemento.

Portanto, a distribuição igual de recursos não é suficiente para corrigir outra fonte de desigualdades imerecidas: a arbitrária distribuição de talentos naturais.

Devemos voltar-nos, portanto, para uma idéia mais conhecida: a redistribuição periódica dos recursos por meio de algum imposto de renda. Convém elaborar um esquema de redistribuição, na medida do possível, que neutralize os efeitos dos talentos diferentes, mas preserve as conseqüencias da escolha de ocupação segundo a noção que a pessoa tem do que deseja fazer da vida $(. . .)^{67}$.

\footnotetext{
65 DWORKIN, R. Virtude soberana, p. 110. Tal posição é mantida especialmente por aqueles que não concebem a união entre igualdade e liberdade, entre os quais estão especialmente os representantes de um, digamos, liberalismo econômico. Segundo estes, a intervenção estatal viola a liberdade individual. Entre os que sustentam tal posição temos, por exemplo, Adam Smith (e sua metáfora da "mão invisível"), F.v. Hayek, Milton Friedman, Robert Nozick, et al.

${ }^{66} \mathrm{Idem}$, p. 111. Além disso, é oportuno mencionarmos o fato de que Dworkin distingue uma "sorte bruta" de uma "sorte por opção": "A sorte por opção diz respeito a resultados de apostas deliberadas e calculadas - isto é, ganhos e perdas de alguém que aceita um risco isolado que devia ter previsto e poderia ter recusado. A sorte bruta diz respeito ao resultado de riscos que não são apostas deliberadas" (p.91).

67 Idem, p. 115.
} 
A propósito, a igualdade da qual nos fala Dworkin refere-se ao "grau de realização das preferências de cada pessoa em relação a sua própria vida e circunstâncias"68. Tal é a "igualdade de bem-estar", a qual não pode ser fundamento de uma concepção de justiça, mas a qual está, contudo, presente nesta (não no âmbito da fundamentação). Isso porque ela envolve o, por assim dizer, telos da filosofia liberal: "tornar sua vida valiosa a seus próprios olhos".

Pelo acima exposto vemos que a metáfora do leilão sugere precisamente esse dispositivo procedimental deontológico com vistas à garantia de uma concepção de justiça que concilie igualdade e liberdade. Em uma situação inicial de igualdade de recursos somos dotados de todos aqueles elementos que nos permitirão fazer uma série de escolhas ao longo de nossa vida em busca de nosso "bem-estar". Ao longo desse processo surgirão, inevitavelmente, desigualdades oriundas não de nossas escolhas ${ }^{69}$, mas de dons naturais desiguais. Daí a necessidade de intervenção estatal. Não apenas isso, é importante que não estejamos sob um 'véu da ignorância' nesse momento de deliberação, pois assim poderemos utilizar de nossos recursos iniciais com vistas às futuras contingências (precavendo-nos contra elas). Dworkin fala mesmo de um "mercado hipotético de seguros"70

Com efeito, o leilão tem como princípio fundamental o seguinte: todos aceitam o princípio de que ninguém tem direito prévio a nenhum dos recursos, mas que devem ser divididos igualmente entre todos ${ }^{71}$. Além disso, temos dois momentos de deliberação: No leilão os recursos são divididos de forma equitativa ('igualdade de recursos') para que cada um disponha dos mesmos recursos para dar "lances" por aquilo que lhe interessa (de acordo com sua "concepção de bem”); em seguida são engendrados “esquemas poste-

\footnotetext{
68 Idem,.p. 27.

${ }^{69} \mathrm{E}$ por estas (resultantes de nossas escolhas) somos responsáveis.

70 "Quem nasce com uma deficiência grave encara a vida com menos recursos, nesse aspecto, do que os outros, conforme admitimos. Essa circunstância justifica a compensação, em um esquema dedicado à igualdade de recursos, e embora o mercado hipotético de seguros não restabeleça o equilíbrio - nada pode fazê-lo - procura remediar um aspecto da desigualdade resultante" (DWORKIN, R. Virtude soberana, p. 101). Tal preocupação está presente mesmo em um autor não-liberal como T. Hobbes. Veja-se, por exemplo, o cap. XXX do Leviathan: "And whereas many men, by accident unevitable, become unable to maintain themselves by their labour; they ought not to be left to the Charity of private persons; but to be provided for, (as far as the necessities of Nature require,) by the Lawes of the Common-wealth*" (HOBBES, T. Leviathan. New York: Penguin Books, 1968, p. 387).

*Note-se que Hobbes usualmente utiliza o termo "estate" para referir-se ao 'estado de natureza', sendo que "Common-wealth" refere-se especialmente ao estado jurídico (civil society, Body politic).

${ }^{71}$ Cf. DWORKIN, R. Virtude soberana. São Paulo: Martins Fontes, 2005. P. 81.
} 
riores de redistribuição": são criadas instituições com vistas à garantia da equidade estabelecida pelo leilão ${ }^{72}$.

Não obstante as diferenças, os modelos de Rawls e de Dworkin trazem consigo um elemento de fundamentação comum: ambos são de jaez kantiano no sentido de que buscam não apenas justificar certos arranjos sociais, políticos e institucionais, mas, sobretudo, por uma legitimação moral do Estado. Há, pois, em ambos, uma busca pela Justiça.

E-mail:ferrazca@hotmail.com

Recebido: 08/2008

Aprovado: 11/08

72 Nesse segundo momento há uma preocupação com a estrutura social, dado que é em torno dela que se organiza a vida social. Ela resulta da cooperação social e dá origem a sistemas educacionais, ao ordenamento jurídico, às instituições políticas e sociais, etc. 